\title{
Air-Seawater Exchange of Organochlorine Pesticides along the Sediment Plume of a Large Contaminated River
}

\author{
Tian Lin, ${ }^{* \dagger}{ }^{\dagger}$ Zhigang Guo, ${ }^{\ddagger}$ Yuanyuan Li, ${ }^{\ddagger}$ Luca Nizzetto, ${ }^{\S}, \|$ Chuanliang Ma, ${ }^{\ddagger}$ and Yingjun Chen ${ }^{\perp}$ \\ ${ }^{\dagger}$ State Key Laboratory of Environmental Geochemistry, Institute of Geochemistry, Chinese Academy of Sciences, Guiyang 550002, \\ China \\ ${ }^{\ddagger}$ Shanghai Key Laboratory of Atmospheric Particle Pollution and Prevention, Department of Environmental Science and Engineering, \\ Fudan University, Shanghai 200433, China \\ ${ }^{\S}$ Research Centre for Toxic Compounds in the Environment (RECETOX), Masaryk University, Brno 62500, Czech Republic \\ "Norwegian Institute for Water Research (NIVA), Oslo 0349, Norway \\ ${ }^{\perp}$ Key Laboratory of Coastal Environmental Processes and Ecological Remediation, Yantai Institute of Coastal Zone Research, Chinese \\ Academy of Sciences, Yantai 264003, China
}

Supporting Information

ABSTRACT: Gaseous exchange fluxes of organochlorine pesticides (OCPs) across the air-water interface of the coastal East China Sea were determined in order to assess whether the contaminated plume of the Yangtze River could be an important regional source of OCPs to the atmosphere. Hexachlorocyclohexanes ( $\mathrm{HCHs}$ ), chlordane compounds (CHLs), and dichlorodiphenyltrichloroethanes (DDTs) were the most frequently detected OCPs in air and water. Air-water exchange was mainly characterized by net volatilization for all measured OCPs. The net gaseous exchange flux ranged 10-240 ng/ $\left(\mathrm{m}^{2} \cdot\right.$ day $)$ for $\gamma-\mathrm{HCH}, 60-370 \mathrm{ng} /\left(\mathrm{m}^{2} \cdot\right.$ day $)$ for trans-CHL, $97-410$ $\mathrm{ng} /\left(\mathrm{m}^{2} \cdot\right.$ day) for cis-CHL, and $\sim 0$ (e.g., equilibrium) to $490 \mathrm{ng} /\left(\mathrm{m}^{2}\right.$. day) for $p, p^{\prime}$-DDE. We found that the plume of the large contaminated river can serve as a significant regional secondary atmospheric source of legacy contaminants released in the catchment. In particular, the sediment plume represented the relevant source of DDT compounds (especially $p, p^{\prime}-\mathrm{DDE}$ ) sustaining net degassing when clean air masses from the open ocean reached the plume area. In contrast, a mass balance showed that, for HCHs, contaminated river discharge (water and sediment) plumes were capable of sustaining volatilization throughout the year. These results demonstrate the inconsistencies in the fate of HCHs and DDTs in this large estuarine system with declining primary sources.

\section{INTRODUCTION}

Oceans are generally considered sinks of atmospheric persistent organic pollutants (POPs). ${ }^{1,2}$ However, an increasing amount of evidence suggests that they can also behave as net atmospheric sources, due to declining concentrations of pollutant in the air, seasonality, and climate change (e.g., reduced ice cover and increased temperatures). ${ }^{2-5}$ Organic matter in the suspended and dissolved phases represents an important component of the total capacity of fugacity for POPs in water bodies. Fugacity is proportional to the thermodynamic activity of a compound in a medium and represents the tendency for the compound to move from a high fugacity state to a low fugacity state. It is therefore a useful concept to describe gaseous exchange of POPs between different environmental compartments. Although the hydrophobic nature of POPs results in a high affinity to particles, re-equilibration of bounded POPs with the dissolved phase during transport and resuspension of contaminated organic sediments can result in high fugacity in the dissolved phase of the receiving coastal waters. In turn, high water phase fugacity can determine the reemission of river-transported contaminants into the air. Testing such a hypothesis requires a detailed assessment of contaminant fate in river estuaries and plume areas, where suspended sediment dynamics are complex and physical conditions change over small spatial/time scales. ${ }^{6-8}$

Organochlorine pesticides (OCPs) are high-concern legacy POPs due to their global occurrence, persistence, and endocrine disrupting activities. ${ }^{9-11}$ Despite primary emissions of OCPs being restricted or banned completely in most parts of the world, large burdens are currently stored in agricultural soils, especially in areas where they were widely used in the

Received: October 20, 2014

Revised: March 19, 2015

Accepted: April 1, 2015

Published: April 1, 2015 

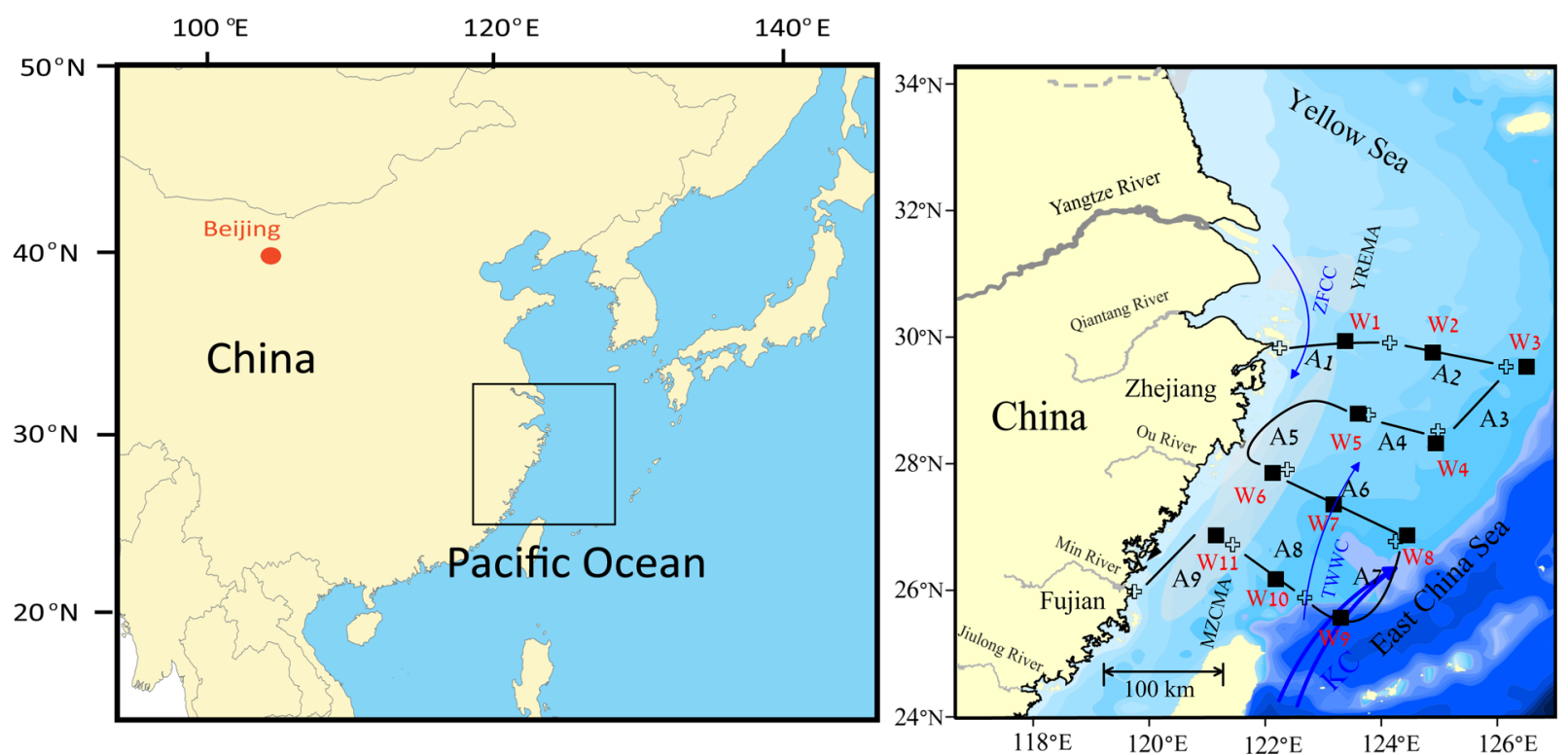

Figure 1. Map of the ECS showing sampling locations (A1-A9, air samples; W1-W11, water samples; KC, Kuroshio current; ZFCC, ZhejiangFujian coastal current; TWWC, Taiwan warm current; YREMA, Yangtze River Estuary mud area; MZCMA, Minzhe coastal mud area).

past. $^{12,13}$ This is the case in China, where OCPs were used in agriculture until $1983 .{ }^{14} \mathrm{~A}$ global ban resulted in a general and significant decline in atmospheric concentrations. ${ }^{13-17}$ Under conditions of declining primary sources, secondary sources become increasingly influential. ${ }^{18}$ Many studies have focused on the effect of declining air concentrations on the re-emission of OCPs from soils directly to the atmosphere. ${ }^{19,20}$ Less is known about lateral remobilization from contaminated soils through superficial and diffuse runoff and riverine transport toward marine coastal environments. In the context of global climate and land use change, soil erosion and riverine transport of contaminated sediments might represent a relevant component of OCP remobilization on local or possibly regional scales. ${ }^{21-23}$ Suspended sediment-bound OCPs in estuaries undergo both incorporation into the sediment bed by particle sedimentation and redistribution between the water and suspended particles, driven by hydrological and physical/ chemical conditions. However, the fate of OCPs in sedimentrich brackish waters has not been investigated fully, and the potential influence of river discharge in driving re-emissions to the atmosphere by sustaining high fugacities in receiving water bodies has not been clarified. Thus, the main objective of this study was to assess the potential role of polluted river plumes as sources of atmospheric OCPs, focusing on the Yangtze River (YR). The YR outflow is recognized as an important secondary source of contaminants (especially OCPs) for the coastal area of the East China Sea (ECS), due to a large sediment plume and considerable past use of OCPs throughout its basin. ${ }^{23}$ The assessment was carried out by estimating air-water diffusive exchange from concentration measurements of selected OCPs taken along a transect extending from the YR estuary mouth to distal sediment depositional areas during the river flood season.

\section{MATERIALS AND METHODS}

2.1. Sampling Location. Sampling locations for the air and water concentration measurements are situated in the coastal ECS (Figure 1). This is a major repository area for the YR suspended sediment plume. The YR is one of the largest rivers in the world by discharge. It annually delivers 900 billion cubic meters of water and 250 million tons of sediments into the ECS. The catchment hosts important agricultural districts where OCPs (in particular DDT and lindane) were intensively used. ${ }^{24}$ More than $80 \%$ of the annual discharge of sediments occurs between June and October, coinciding with the flood season. This leads to the accumulation of the Yangtze-derived sediments in the delta and estuarine system, forming the Yangtze River Estuary mud area (YREMA) (Figure 1). ${ }^{25,26}$ In winter, strong wind-induced waves readily resuspend fine particles of the newly deposited sediments in the YREMA that are then transported southward along the inner shelf by the southward Zhejiang-Fujian coastal current (ZFCC). This material is then constrained by the northward flowing Taiwan warm current (TWWC) to the inner shelf of the ECS and is accumulated in the Minzhe coastal mud area (MZCMA) (Figure 1). ${ }^{25,26}$ Other sediment inputs from small rivers south of the YR, such as the Qiantang River, the Ou River, and the Min River, and aerosol/dust only make a relatively small contribution $(<5 \%)$ to the mud wedge compared to those originating from the $\mathrm{YR}^{27}$

2.2. Sample Collection. A total of 9 air samples were taken daily during 10 days in September 2012 on board of the research vessel SCIENCE III. The cruise route and sampling locations are shown in Figure 1. A high volume air sampler for total suspended particulates at a flow rate of $250 \mathrm{~L} / \mathrm{min}$ (Guangzhou Mingye Technology Company) was placed on the upper-most deck of the ship, approximately $10 \mathrm{~m}$ above sea level and operated in upwind conditions in relation to the ship smoke stack emissions. Each sample was collected during about $24 \mathrm{~h}$ : therefore, despite the limited number of samples, the atmospheric concentration data collected here represent the results of a continuous monitoring. Air volumes of approximately $300 \mathrm{~m}^{3}$ were drawn through a quartz fiber filter (QFF) $(20 \mathrm{~cm} \times 25 \mathrm{~cm}$, Pall Gelman, USA) and two polyurethane foam (PUF) plugs $(6.5 \mathrm{~cm}$ in diameter, $7.5 \mathrm{~cm}$ in thickness, density of $0.030 \mathrm{~g} / \mathrm{cm}^{3}$ ) (refer to the Supporting Information, Text 2.2, for more details).

A total of 11 surface seawater samples, each of approximately $50 \mathrm{~L}$, was collected using a metal bucket (Figure 1). Collected 
water was immediately filtered through precombusted $(4 \mathrm{~h}$ at $450{ }^{\circ} \mathrm{C}$ ), $150 \mathrm{~mm}$ diameter QFFs (Gelman Type A/E, nominal pore size $1 \mu \mathrm{m}$, Pall Gelman, USA), while the dissolved phase pesticides were extracted on solid phase using an Amberlite XAD-2 and XAD-4 mixture (1:1, Sigma-Aldrich, USA) in a glass column ( $25 \mathrm{~mm}$ i.d., $200 \mathrm{~mm}$ long). The methodology for the preparation and handling of the sorbent phase is described in detail in Text S2.2 (Supporting Information).

In this study, air temperature, surface water temperature and salinity, and wind speed and direction were measured using ship-integrated sensors. Data are presented in Table S1 (Supporting Information).

2.3. Sample Treatment, Analytical Procedure, and Quality Control. Target analytes included 16 compounds: $\alpha$ $\mathrm{HCH}, \beta-\mathrm{HCH}, \gamma-\mathrm{HCH}, \delta$-HCH, $p, p^{\prime}$-DDT, $o, p^{\prime}$-DDT, $p, p^{\prime}-$ DDE, $p, p^{\prime}$-DDD, trans-chlordane (trans-CHL), cis-chlordane (cis-CHL), heptachlor, $\alpha$-endosulfan, $\beta$-endosulfan, aldrin, dieldrin, and endrin. The treatment and analytical procedure for eluting OCPs from PUF and XAD samples was described in detail elsewhere. ${ }^{16,17}$ Adopted quality assurance and control measures are described in Text S2.3 (Supporting Information).

2.4. Back Trajectories. The origin of air masses reaching the sampling locations was investigated using the HYSPLIT model (HYbrid Single-Particle Lagrangian Integrated Trajectory, Version 4.7) developed by the NOAA Air Resource Laboratory. Five day backward trajectories calculated at the beginning and end of each air sampling event were computed starting from the ship location at 500, 700, and $1500 \mathrm{~m}$ above sea level (Figure S3, Supporting Information). Back trajectories at altitudes of 500 and $700 \mathrm{~m}$ were considered to trace longrange and continental air mass transport in this study.

2.5. Air-Water Exchange Flux Calculation. The Whitman two-film resistance model was used to calculate the airwater exchange flux. This model was previously used in many studies of the air--sea exchange of POPs. ${ }^{28-32}$

The air-water exchange flux $\left(F_{\mathrm{w}-\mathrm{a}}\right)$ is given by

$$
F_{\mathrm{w}-\mathrm{a}}=K_{\mathrm{ol}}\left(C_{\mathrm{d}, \mathrm{w}}-C_{\mathrm{g}, \mathrm{a}} / H^{\prime}\right)
$$

where $K_{\mathrm{ol}}(\mathrm{m} /$ day $)$ is the overall mass transfer coefficient describing the rate of transfer from water to air through the complete diffusive path between air and surface water, $C_{\mathrm{d}, \mathrm{w}}$ is the concentration of OCP in the dissolved phase $\left(\mathrm{ng} / \mathrm{m}^{3}\right)$, and $C_{\mathrm{g}, \mathrm{a}}$ is the concentration in the gas phase $\left(\mathrm{ng} / \mathrm{m}^{3}\right) . H^{\prime}$ is the temperature and salinity-corrected dimensionless Henry's law constant. Salinity and temperature correction was performed as described elsewhere. ${ }^{33}$ Data on $H^{\prime}$ values and temperature dependence were taken from refs 34 and 35 .

$K_{\mathrm{ol}}$ is the overall mass transfer coefficient accounting for the contributions from the mass transfer coefficients of the water layer and the air layer, namely, $k_{\mathrm{w}}$ and $k_{\mathrm{a}}$, as follows:

$$
1 / K_{\mathrm{ol}}=1 /\left(H^{\prime} \times k_{\mathrm{a}}\right)+1 / k_{\mathrm{w}}
$$

where $k_{\mathrm{w}}$ and $k_{\mathrm{a}}$ are related to the compound specific molecular diffusion coefficients and kinematic phase viscosities via the Schmidt numbers for a chemical in water and air, respectively, and a wind speed at a reference height of $10 \mathrm{~m}$. The mathematical frame for the calculation of $K_{\mathrm{ol}}$ is reported in detail in Text S2.5 (Supporting Information).

In order to obtain information on $C_{\mathrm{d}, \mathrm{w}}$, results of dissolved concentrations from the $\mathrm{XAD}$ cartridges were corrected by the estimated influence of sorption by dissolved organic carbon in water as follows:

$$
C_{\mathrm{d}, \mathrm{w}}=C_{\mathrm{XAD}} /\left(1+K_{\mathrm{DOC}}[\mathrm{DOC}]\right)
$$

where $C_{\mathrm{XAD}}\left(\mathrm{ng} / \mathrm{m}^{3}\right)$ is the water concentration from $\mathrm{XAD}$ samples, $K_{\mathrm{DOC}}$ is the dissolved organic carbon-water equilibrium partitioning coefficient $\left(\mathrm{m}^{3} / \mathrm{kg}\right)$, and [DOC] is the concentration of dissolved organic carbon in marine water $\left(\mathrm{kg} / \mathrm{m}^{3}\right)$. The parametrization of $K_{\mathrm{DOC}}$ is highly uncertain. As a first approximation, we adopted in this study the one proposed by Poerschmann and Kopinke. ${ }^{36}$ DOC concentration data for the ECS were taken from Hung et al. ${ }^{37}$

\section{RESULTS AND DISCUSSION}

3.1. OCP Concentration in Seawater. $\alpha-\mathrm{HCH}, \gamma-\mathrm{HCH}$, trans-CHL, cis-CHL, and $p, p^{\prime}$-DDE were detected in all samples. $p, p^{\prime}$-DDT, $o, p^{\prime}$-DDT, and $p, p^{\prime}$-DDD were detected in $73-81 \%$ of samples (Table S2, Supporting Information). The other pesticides were hardly detected or not detected in this study. The total dissolved-phase concentrations of eight detectable OCPs were 315-1635 pg/L with a mean of $925 \mathrm{pg} /$ L. Typically, the average dissolved-phase concentration represented more than $90 \%$ of the total OCP in the water (dissolved + particle). This result agrees well with previously reported data from the ECS. ${ }^{17}$ The dissolved-phase concentrations of individual OCPs were (with the mean provided in parentheses) $110-1100$ (460) pg/L for $\gamma-\mathrm{HCH}$, not detectable (n.d.) -220 (129) pg/L for $p, p^{\prime}-\mathrm{DDE}, 19-310$ (83) pg/L for $\alpha$ $\mathrm{HCH}, 30-170$ (75) pg/L for cis-CHL, 24-160 (69) pg/L for trans-CHL, n.d.-100 (45) pg/L for $p, p^{\prime}-\mathrm{DDT}$, n.d.-58 (30) $\mathrm{pg} / \mathrm{L}$ for $o, p^{\prime}-\mathrm{DDT}$, and n.d.-24 (8) pg/L for $p, p^{\prime}-\mathrm{DDD}$. In general, the water concentration levels measured in this study were within the same range as previously reported data from coastal areas in China, and 1-2 orders of magnitude lower compared to water concentrations from Chinese rivers flowing into the ECS. ${ }^{17,38-40}$ From a broader perspective, the water concentrations of the ECS were at the higher end of the spectrum of marine water concentration data from different coastal locations around the world (Table S4, Supporting Information).

The high detection frequency and abundance of $\gamma-\mathrm{HCH}$ and $p, p^{\prime}$-DDE can be attributed to high historical usage of lindane and technical DDT in China. ${ }^{14,41}$ Also, CHL production began in 1960 in China, and the pesticide was produced over the next 50 years mainly by nine manufacturers located in East China. Between 1988 and 2008, the total CHL usage in China was 2745 tons, accounting for approximately $80 \%$ of the total national production in that period, and Zhejiang Province on the East China coast (directly facing the sampling region) was the largest consumer in China. ${ }^{42,43}$ Concentrations and contamination profiles suggest that OCPs in the selected coastal areas were influenced by land-based sources from highly polluted agricultural areas of China.

Previous results showed that the highest sedimentation rates $(>2.0 \mathrm{~cm} / \mathrm{yr})$ were found in the estuary of the YR and tended to decrease alongshore toward the south. Sediment resuspension and transport result in a portion of finer-grained, organic carbon-rich sediments being transported longer distances and mainly deposited in the MZCMA. ${ }^{25-27,44}$ This behavior was key to explaining the higher sediment concentrations of POPs (e.g., HCHs, DDTs, short-chain chlorinated parafins, and polybrominated diphenyl ethers) and polycyclic aromatic hydrocarbon observed in the MZCMA (compared to the YREMA) in previous studies. ${ }^{23,45-47}$ A consistent pattern can be observed here looking at water concentration results (Figure 

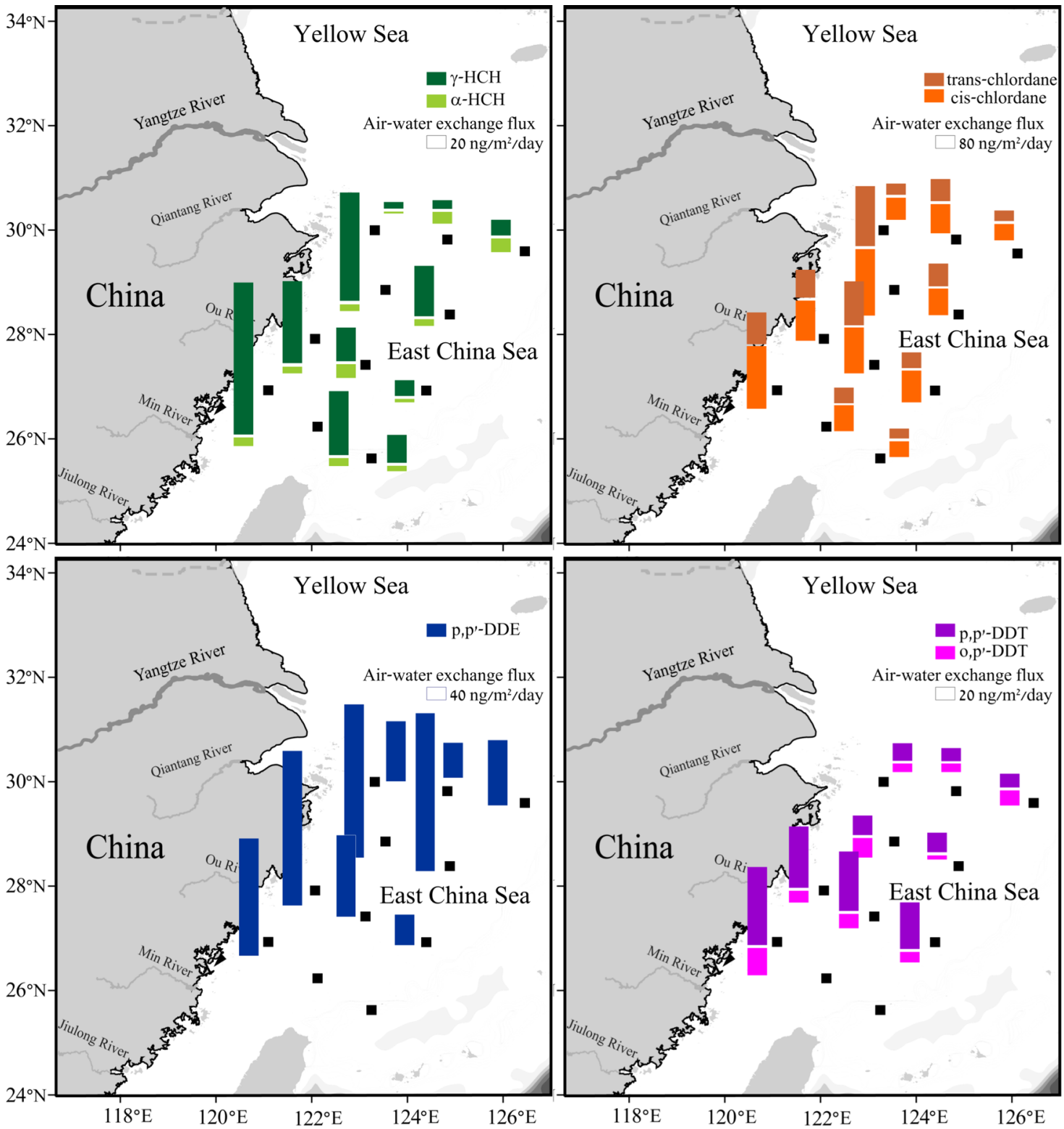

Figure 2. Spatial distributions of air-water exchange flux (net volatilization) of individual OCPs in the ECS.

S1, Supporting Information), suggesting the possible control of sediments and suspended particles over the high levels of dissolved phase OCPs in the MZCMA. In addition, the concentrations of OCPs in seawater generally showed a decreasing trend moving away from the shore. This pattern reflected the main trajectory of the YR plume along the coast with increasing (toward the offshore) influence of the TWWC, which constrains sediments in the coastal depositional areas and progressively dilutes the plume (see Figure 1). This scenario is strongly supported by low levels of OCPs observed in the water at sites W8-W10, which are located in the southern part of the sampling area and affected by the Kuroshio current. This is a strong western boundary current driving the (relatively clean) open ocean water northward along the distal shelf slope of the ECS (see Figure 1).

3.2. Atmospheric Concentrations of OCPs. The most frequently detected OCPs in the gas phase also were $\alpha-\mathrm{HCH}$, $\gamma$-HCH, trans-CHL, cis-CHL, $p, p^{\prime}$-DDE, $p, p^{\prime}$-DDT, $o, p^{\prime}$-DDT, and $p, p^{\prime}$-DDD (Figure S2 and Table S2, Supporting
Information). The particulate bound fraction was less than $10 \%$ of the total for most of the targeted chemicals.

The concentrations of $\gamma-\mathrm{HCH}$ and $\alpha-\mathrm{HCH}$ ranged from 14 to $120(53) \mathrm{pg} / \mathrm{m}^{3}$ and from 11 to $63(25) \mathrm{pg} / \mathrm{m}^{3}$, respectively. The $\mathrm{HCH}$ concentrations measured were consistent with previous observations in coastal areas of China, showing no further decline over the past decade. ${ }^{17,48} \alpha-\mathrm{HCH}$ concentrations in the atmosphere over the Chinese marginal seas have been relatively low, since technical $\mathrm{HCH}$ was restricted more than two decades ago. However, because of the higher volatilization of $\alpha-\mathrm{HCH}$ and/or phototransformation of $\gamma$ $\mathrm{HCH}$ into $\alpha-\mathrm{HCH}, \alpha-\mathrm{HCH}$ was still the most frequently detected $\mathrm{HCH}$ isomer in the air. These concentrations were comparable to those found in the atmosphere above adjacent regions such as Singapore $\left(84 \pm 33 \mathrm{pg} / \mathrm{m}^{3}\right.$ in 2006) and South Korea (n.d. $-84 \mathrm{pg} / \mathrm{m}^{3}$, in 2008-2009) ${ }^{49,50}$ and comparable or slightly higher than background atmospheric concentrations from open oceans (the North Pacific Ocean and the adjacent Arctic region in $2003\left(0.2-49 \mathrm{pg} / \mathrm{m}^{3}\right)$ and $2008(13 \pm 7.5 \mathrm{pg} /$ 
$\left.\mathrm{m}^{3}\right)$, the Atlantic Ocean in $2001\left(\sim 3.6-100 \mathrm{pg} / \mathrm{m}^{3}\right)$, the Indian Ocean in 2004-2005 $\left(2.3-80 \mathrm{pg} / \mathrm{m}^{3}\right)$, the North Atlantic and Arctic Ocean in $2004\left(\sim 1-10 \mathrm{pg} / \mathrm{m}^{3}\right)$, the Canadian Arctic $\left(2.1-7.7 \mathrm{pg} / \mathrm{m}^{3}\right)$ in 2008, and the Southern Ocean and Antarctic Peninsula in $\left.2008-2009\left(1.5-7.1 \mathrm{pg} / \mathrm{m}^{3}\right)\right) .^{51-57}$

The concentrations of $p, p^{\prime}-\mathrm{DDE}$ were $19-56(30) \mathrm{pg} / \mathrm{m}^{3}$. These values are comparable to those observed in the North Pacific Ocean and the adjacent Arctic region in 2003 (0.18-42 $\mathrm{pg} / \mathrm{m}^{3}$ ) and in 2008 (n.d. $\left.-16 \mathrm{pg} / \mathrm{m}^{3}\right),{ }^{, 1,54}$ the open Atlantic Ocean in $2001\left(\sim 1.5-47 \mathrm{pg} / \mathrm{m}^{3}\right),{ }^{52}$ and the North Atlantic and Arctic Ocean in $2004\left(0.1-16 \mathrm{pg} / \mathrm{m}^{3}\right) .{ }^{53}$ Similarly, the concentrations of $o, p^{\prime}$-DDT and $p, p^{\prime}$-DDT ranged from n.d. to $27(8) \mathrm{pg} / \mathrm{m}^{3}$ and from n.d. to 14 (4) $\mathrm{pg} / \mathrm{m}^{3}$, respectively, and were comparable with those from the North Pacific Ocean and the adjacent Arctic region in $2003\left(0.19-73 \mathrm{pg} / \mathrm{m}^{3}\right.$ for $o, p^{\prime}$-DDT and $0.20-110 \mathrm{pg} / \mathrm{m}^{3}$ for $p, p^{\prime}$-DDT) and in 2008 (n.d. $-30 \mathrm{pg} / \mathrm{m}^{3}$ and n.d. $-54 \mathrm{pg} / \mathrm{m}^{3}$, respectively), ${ }^{51,54}$ the open Atlantic Ocean $\left(<2.2-5.4 \mathrm{pg} / \mathrm{m}^{3}\right.$ for $p, p^{\prime}$-DDT $){ }_{55}^{52}$ and the open Indian Ocean $\left(0.2-26 \mathrm{pg} / \mathrm{m}^{3}\right.$ for $p, p^{\prime}$-DDT $){ }^{55}$

Measured atmospheric concentrations of trans- and cis-CHL ranged from 62 to $320(135) \mathrm{pg} / \mathrm{m}^{3}$ and from 110 to 500 (240) $\mathrm{pg} / \mathrm{m}^{3}$, respectively. These concentrations were significantly lower than those in the Northern South China Sea in 2005 $\left(510 \pm 650 \mathrm{pg} / \mathrm{m}^{3}\right.$ for trans-CHL and $450 \pm 620 \mathrm{pg} / \mathrm{m}^{3}$ for cisCHL). ${ }^{16}$

Combined, these results indicate a contamination profile typical of background open sea areas rather than land-based sources in China and adjacent areas. The ratios of $\alpha-\mathrm{HCH} / \gamma$ $\mathrm{HCH}$ isomers and trans- $\mathrm{CHL} / \mathrm{cis}$ - $\mathrm{CHL}$ were used to identify the possible sources and residence times in the environment. Generally, a ratio of trans-CHL/cis-CHL was found to range between 1.1 and 1.3 in the technical chlordane mixture used in China, and a high $\alpha / \gamma$ ratio of $\mathrm{HCHs}$ should indicate the input of technical $\mathrm{HCH}$ and a low ratio for the use of lindane. ${ }^{58}$ In this study, the differences between the ratios in water and in air were significant, that is, $0.23 \pm 0.31$ in water versus $0.60 \pm 0.23$ in air for $\alpha-\mathrm{HCH} / \gamma-\mathrm{HCH}$ and $0.92 \pm 0.23$ in water versus 0.54 \pm 0.18 in air for trans-CHL/cis-CHL, suggesting that these pollutants were derived from different sources or transport pathways. Considering that trans-CHL is more susceptible to photodegradation than cis- $\mathrm{CHL}$ and $\gamma$ - $\mathrm{HCH}$ undergoes phototransformation into $\alpha-\mathrm{HCH},{ }^{58-60}$ the relative higher abundances of cis-CHL and $\alpha-\mathrm{HCH}$ in the air indicate that they underwent long-term degradation or volatilization from water to air. In addition, Ding et al. also noticed an increasing trend in ratios of $\alpha-\mathrm{HCH} / \gamma-\mathrm{HCH}$ with air transport because $\gamma-\mathrm{HCH}$ was more easily removed on the way. ${ }^{15}$ This is confirmed by the results of the five day back-trajectory simulations showing that air masses of open sea origin mainly originated from offshore areas in the Southern Korean Peninsula and Southern Japan. Such an exposure scenario resulted in relatively homogeneous levels of OCPs in the atmosphere across the whole study area. Exceptionally, air masses sampled in A7 and A8 indicated that the sampled air passed through a higher contaminated region of East China before reaching the sampling location (Figure S3, Supporting Information). Indeed, relatively high levels of all OCPs (especially $\gamma-\mathrm{HCH}$, trans$\mathrm{CHL}$, cis-CHL, and $p, p^{\prime}$-DDE) were measured in these samples, which were therefore identified as representative of air masses carrying the signal of Chinese land-based sources.

3.3. Air-Water Exchange. Estimated $F_{\mathrm{w}-\mathrm{a}}$ values were consistently positive throughout the sampling period, suggesting that air-water exchange was dominated by net volatilization
(Figure 2). To acknowledge the aggregated uncertainty associated with the calculation of the fugacity ratios (a large part of which is dependent on the uncertainty in the value of $H^{\prime}$ and to a minor extent on measurement errors ${ }^{61}$ ), only measurements for which the ratio of $C_{\mathrm{g}, \mathrm{a}} / H^{\prime} / C_{\mathrm{d}, \mathrm{w}}$ was higher than 3 were assumed to indicate net volatilization. The net volatilization (or near equilibrium conditions) flux values ranged as follows: $\sim 0-490 \mathrm{ng} /\left(\mathrm{m}^{2} \cdot\right.$ day $)$ for $p, p^{\prime}$-DDE, 97$410 \mathrm{ng} /\left(\mathrm{m}^{2} \cdot\right.$ day $)$ for cis-CHL, $60-370 \mathrm{ng} /\left(\mathrm{m}^{2} \cdot\right.$ day $)$ for trans$\mathrm{CHL}, 10-240 \mathrm{ng} /\left(\mathrm{m}^{2} \cdot\right.$ day $)$ for $\gamma-\mathrm{HCH}$, and $\sim 0-120 \mathrm{ng} /\left(\mathrm{m}^{2}\right.$. day) for $p, p^{\prime}$-DDT. Lower volatilization fluxes were observed for $o, p^{\prime}$-DDT $\left(\sim 0-42 \mathrm{ng} /\left(\mathrm{m}^{2} \cdot\right.\right.$ day $\left.)\right), \alpha-\mathrm{HCH}\left(2-21 \mathrm{ng} /\left(\mathrm{m}^{2}\right.\right.$. day)), and $p, p^{\prime}$-DDD $\left(\sim 0-12 \mathrm{ng} /\left(\mathrm{m}^{2} \cdot\right.\right.$ day $\left.)\right)$ (Figure 2$)$.

Confidence in the magnitude of calculated fluxes was traced from the estimated uncertainties of measured and modeled parameters. The relative standard error for both $C_{\mathrm{g}, \mathrm{a}}$ and $C_{\mathrm{d}, \mathrm{w}}$ measurements was assumed to be $\pm 15 \%$, which was adopted based on the results from repeatedly analyzing the standard reference material in our lab. According to the regression parameters for the equation $\ln H=A+B / T(K)$ for saline water given in Cetin et al., ${ }^{33}$ the uncertainty in the $H$ values for selected OCPs was estimated from $\pm 59 \%$ (for cis-CHL) to $\pm 13 \%$ (for $p, p^{\prime}$-DDT). The estimated influence of sorption by DOC in water was calculated to be less than $10 \%$ for DDTs and negligible for $\mathrm{HCHs}$. Considering such a relative small influence on flux results, the uncertainty associated with DOC sorption estimates was also considered negligible. Wind speed has a deep influence on the $K_{\mathrm{ol}}$ result. To estimate the variance of flux across different wind-speed conditions, repeated calculations were conducted using data on maximum and minimum wind speeds measured during the sampling. For example, the change in the volatilization flux of $p, p^{\prime}$-DDE ranged from $90 \pm 84 \mathrm{ng} /\left(\mathrm{m}^{2}\right.$.day $)$ for the minimum wind speed to $242 \pm 187 \mathrm{ng} /\left(\mathrm{m}^{2}\right.$.day $)$ for the maximum wind speed. The overall uncertainty for flux measurements (including measurement errors, physical-chemical property errors, and wind-speed-associated variance) was therefore estimated to be between $\pm 140 \%$ and $\pm 90 \%$ of the reported mean value, depending on the compound. The flux estimates are therefore expected to capture the order of magnitude of the air-water exchange.

After the ban on technical DDT, the residue in agricultural soils acted as an important source of DDTs. Enhanced land soil erosion from the process of large-scale land transformation in the basin, as well as a higher river water flow in the flood season, had mobilized these DDTs (especially $p, p^{\prime}$-DDE) from the soil to the water environment in the area. cis-CHL and trans-CHL also exhibited high net volatilization fluxes out of the water, although these chemicals are still used in China. Technical CHL was mainly used for termite control in buildings and forests using the surface soil burial method or discharged as waste from manufacturing plants in East China, so it would be more inclined to enter the water by way of runoff rather than the ambient atmosphere, after its primary emission. ${ }^{17}$ The fugacity ratios for $\gamma-\mathrm{HCH}$ suggested net volatilization of air-water fluxes in the coastal ECS. The OCPs of different background usages exhibited net volatilization, suggesting that there was a large source of these contaminants in the water, driving re-emission to the air. YR runoff is one logical candidate for a large contribution to the coastal ECS capable of sustaining net volatilization during this period.

3.4. Assessing the Importance of Air-Water Exchange in Controlling Air Mass Concentrations. The 
effectiveness of re-emission from seawater in controlling air loads of contaminants can be assessed by the relationship between wind speed and atmospheric concentration. Since the atmospheric concentration measurements were conducted directly at the site of the hypothetical dominant source location, we expected to observe an inverse relationship between wind speed and atmospheric concentration. ${ }^{62,63}$ The experimental data reflect this, showing evidence of an inverse relationship between these two parameters (Figure 3). High

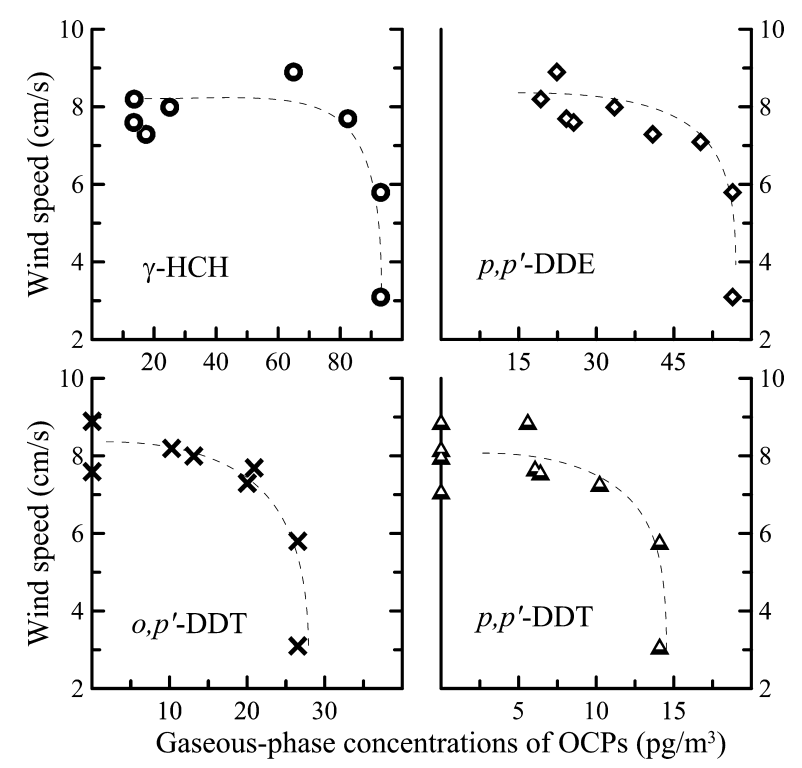

Figure 3. Relationship of gaseous-phase concentrations of OCPs with wind speed during the cruise in the coastal ECS (the dotted line represents a best-fit nonlinear correlation).

values of $K_{\mathrm{ol}}$ under high-speed wind enhance the kinetics of pesticide degassing from the sea surface. However, such a kinetic gain is effectively offset by rapid dilution via high-speed wind. This antagonistic effect was expected to produce complexity in the relationship between wind speed and air concentration, which is highlighted by the scattered and nonlinear character of the plots of Figure 3.

Moreover, the ratios of $\alpha-\mathrm{HCH} / \gamma-\mathrm{HCH}$ isomers and trans$\mathrm{CHL} /$ cis-CHL under low-speed wind conditions ( 0.28 for $\alpha$ $\mathrm{HCH} / \gamma-\mathrm{HCH}$ and 0.84 for trans-CHL/cis-CHL) differed from those under high-speed wind conditions $(0.47-0.96$ for $\alpha$ $\mathrm{HCH} / \gamma-\mathrm{HCH}$ and $0.31-0.71$ for trans-CHL/cis-CHL) but were similar to those in water, that is, $0.23 \pm 0.31$ for $\alpha-\mathrm{HCH} /$ $\gamma$ - $\mathrm{HCH}$ and $0.92 \pm 0.23$ for trans-CHL/cis-CHL. Low values of the ratios under low wind-speed conditions reflected the influence from the local source (e.g., surface water emission) while higher ratios under high wind-speed conditions reflected background contamination profiles and were observed when air masses were from the open ocean.

In summary, the pattern observed here is consistent with the scenario of an influential active source (in this case, volatilization from the seawater surface) in a boundary condition, where background low-contaminated air is blown into an area with high water fugacities. The intensity of volatilization from the seawater surface appears to be sufficient to control atmospheric levels in a low-speed wind environment when air masses originated from the open sea.

3.5. Relevance of River Plume and Degassing as Sources and Sinks for the Water Column. To further explain the observed volatilization, it is necessary to assume the presence of a relevant source of OCP in water capable of sustaining relatively high water fugacities over time. In this study, the delineated scenario with dominant volatilization of OCPs in the main depositional area of the YR sediment plume may be the result of two possible sources (individually or in combination): (i) the atmosphere as a dominant source of OCPs for seawater during periods in which contaminated air masses originated from the Chinese mainland, shifting to revolatilization when the air mass provenience is the open sea, and (ii) the river plume as a dominant source. Other possible local sources for the water column include emissions from old ship paints and local illicit use of pesticides. ${ }^{64,65}$ However, these sources can be considered negligible due to the relatively large scale of the assessment. In synthesis, hypothesis (i) states that the observed volatilization is the simple result of contingent temporary unsteady conditions in the air/water fugacity ratio, dependent on air mass provenience. Hypothesis (ii) states that the river plume (at least during flooding periods) exerts a strong control on water contamination determining high water fugacities.

To assess the possible relevance of these two scenarios, a simplified mass balance exercise was conducted aimed at comparing river plume inputs to the major repository area with estimated sedimentary fluxes and volatilization fluxes measured. The mass balance focused on $\alpha-\mathrm{HCH}, \gamma-\mathrm{HCH}, p, p^{\prime}$-DDE, and $p, p^{\prime}$-DDT, which were widely detected in the estuarine (e.g., the YR and the Qiantang River) and the coastal area (Table S3, Supporting Information). Here, the control area was limited by the coastal ECS containing the YREMA and the MZCMA. This area has a total surface of $\sim 100000 \mathrm{~km}^{2}$. The input process considered here was the outflow of contaminants from the YR and adjacent smaller rivers. Considered sink processes included settling with burial into sediment beds (estimated from recently published data ${ }^{23}$ ) and measured volatilization fluxes. Degradation was considered negligible, since fluxes were integrated over a short time period (one year) while both DDTs and $\mathrm{HCHs}$ have half-lives in water on the order of several years. ${ }^{66}$

The YR annually discharges 900 billion cubic meters of water and 250 million tons of sediment into the coastal areas of the ECS. As a first-order conservative approximation, it was assumed that $80 \%$ of the sediment plume is eventually transported into the control area. ${ }^{25,26}$ On the basis of these discharge rates and total DDT concentrations (sum of $p, p^{\prime}$ DDE, $p, p^{\prime}$-DDT, and $o, p^{\prime}$-DDT) measured at the river estuary level $(2 \mathrm{ng} / \mathrm{L}$ and $16 \mathrm{ng} / \mathrm{g}$ for the dissolved phase and suspended sediment bounded fraction, respectively ${ }^{40}$ ), it was estimated that the total annual effluxes of DDTs to the control area are 1.8 and 4 tons/yr for the water phase and the sediment phase, respectively (Figure 4 and Table S3, Supporting Information). Similarly, the annual inputs of dissolved and particulate $\mathrm{HCHs}$ (sum of $\alpha-\mathrm{HCH}$ and $\gamma-\mathrm{HCH}$ ) to the control area were estimated to be 3.15 and 0.6 tons/yr, respectively (based on the concentrations of $3.5 \mathrm{ng} / \mathrm{L}$ and $2.5 \mathrm{ng} / \mathrm{g}^{40}$ ). The effluxes from other small rivers with estuaries located to the south of the YR (i.e., the Qiantang River) were 0.18 ( 0.10 and 0.08 for water and sediment discharges) and 0.74 (0.60 and 0.14 ) tons/yr for DDTs and HCHs, respectively (See Figure 4 and Table S3, Supporting Information).

The estimated sedimentary fluxes of DDTs and HCHs in the control area were 3.0 and 0.60 tons/yr in the coastal ECS, respectively, which is lower than the total fluxes from sediment discharge of the YR and the Qiantang River (4.1 and 0.74 tons/ 


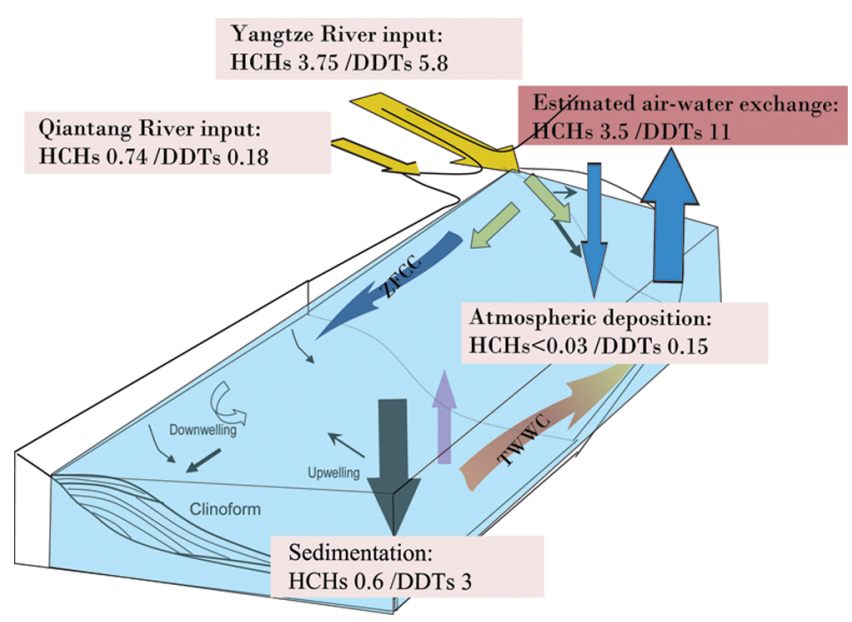

Figure 4. General fluxes of DDTs and HCHs in the coastal ECS (tons/yr).

yr; see Figure 4 and Table S3, Supporting Information). Consequently, DDTs and HCHs entering the coastal ECS in the dissolved phase (or by water discharge) tend to build high fugacity in the water column rather than being effectively buried in the sediments. If fluxes from associated particles and freely dissolved contaminants are bulked together for consideration (6.0 and 4.5 tons/yr for DDTs and HCHs, respectively), the exchange of these chemicals between suspended particles and the dissolved phase can be assumed to be sufficiently rapid, with nearly no kinetic limit to the refilling of the dissolved phase water reservoir through forcing from air-water exchange. $^{28}$

According to air-water exchange fluxes during the period of this study, net volatilization from the control areas was estimated to be 3.5 tons/yr for HCHs ( 0.58 tons/yr for $\alpha$ $\mathrm{HCH}$ and 2.92 tons/yr for $\gamma-\mathrm{HCH}$ ) and 11 tons/yr for DDTs (8.3 tons/yr for $p, p^{\prime}$-DDE, 1.7 tons/yr for $p, p^{\prime}$-DDT, and 1 tons/yr for $o, p^{\prime}$-DDT; Table S3, Supporting Information). The volatilization of $\alpha-\mathrm{HCHs}$ and $\gamma-\mathrm{HCH}$ observed could alone justify the mass balance closure, showing that degassing from surface water is enhanced by exposure to low-contaminated air masses of marine origin and volatilization can dissipate a large fraction of the total contaminant plume reaching the control area. Since $\mathrm{HCHs}$ from the YR and adjacent smaller rivers existed mainly in the dissolved phase, even under periods in which air masses originated from the continent with a prevailing northwest monsoon, low re-emission fluxes of $\mathrm{HCHs}$ were observed from surface water. It was estimated that over $70 \%$ of the river-derived $\mathrm{HCHs}$ could have been released from the water column into the air via air-water exchange, showing that marine surface water is an important regional source of $\mathrm{HCHs}$ for the atmosphere of the coastal ECS. Considering the main direction of atmospheric advection in different periods of the year, only a fraction of the $\mathrm{HCHs}$ can return back to the inland, while the rest is delivered to the open sea atmosphere.

For $p, p^{\prime}$-DDE and $p, p^{\prime}$-DDT, the balance between river plume sources, sedimentation, and volatilization resulted in a large offset for $p, p^{\prime}$-DDE, with volatilization largely exceeding river plume input (by a factor $>2$; Table S3, Supporting Information). This suggests that river plumes alone cannot sustain the volatilization fluxes of $p, p^{\prime}$-DDE over a full year and that the observed re-emission might be subordinated to episodic exposure to air masses originating from lowcontaminated areas of the open sea (corroborating hypothesis (i)). This scenario was supported by air/water fugacity measurements at stations A7 and A8 (with land-originated air masses) that showed equilibrium (Figure 2). Because of the prevailing westerly origin of air masses over midlatitudes of Northeast Asia, the main advection pattern for atmospheric pollutants is from land to ocean. It is important to note that, during winter, there is a high air concentration of particulate $p, p^{\prime}$-DDE adsorbed on dust particles, due largely to the high abundance of weathered DDTs stored in agricultural soils. Therefore, the river sediment plume source and the atmospheric deposition play a role in determining high fugacity levels in water; however, such a source does not appear to be sufficiently strong to sustain the observed volatilization fluxes over long periods of time. The reciprocal influence of the river plume source and the continental outflow is expected to periodically shift as a result of seasonality and air mass origin.

\section{ASSOCIATED CONTENT}

\section{S Supporting Information}

Details on chemical analysis methodology, the full experimental data set of concentrations, and flux for input and output pathways of individual OCPs in the coastal ECS. This material is available free of charge via the Internet at http://pubs.acs.org.

\section{AUTHOR INFORMATION}

\section{Corresponding Author}

*Phone/fax: (86)-851-85895239; e-mail: lintian@vip.gyig.ac. cn.

\section{Notes}

The authors declare no competing financial interest.

\section{ACKNOWLEDGMENTS}

The authors appreciate the financial support from the National Natural Science Foundation of China (NSFC) (nos: 41103046 and 41176085), partially funded by the State Key Laboratory of Environmental Geochemistry, Institute Of Geochemistry, CAS. Part of the work was carried out with the support of the core facilities of RECETOX - National Infrastructure, project number LM2011028, funded by the Ministry of Education, Youth and Sports of the Czech Republic under the activity "Projects of major infrastructures for research, development and innovations". The National Oceanic and Atmospheric Administration's Air Resources Laboratory is also gratefully acknowledged for the provision of the HYSPLIT transport and dispersion model used in this study.

\section{REFERENCES}

(1) Iwata, H.; Tanabe, S.; Sakai, N.; Tatsukawa, R. Distribution of persistent organochlorines in the oceanic air and surface seawater and the role of ocean on their global transport and fate. Environ. Sci. Technol. 1993, 27, 1080-1098.

(2) Stemmler, I.; Lammel, G. Cycling of DDT in the global environment 1950-2002: World ocean returns the pollutant. Geophys. Res. Lett. 2009, 36, L24602.

(3) Jantunen, L. M.; Helm, P. A.; Kylin, H.; Bidleman, T. F. Hexachlorocyclohexanes (HCHs) in the Canadian archipelago. 2. Airwater gas exchange of $\alpha$ - and $\gamma-\mathrm{HCH}$. Environ. Sci. Technol. 2007, 42 (2), 465-470.

(4) Hung, H.; Kallenborn, R.; Breivik, K.; Su, Y.; Brorström-Lundén, E.; Olafsdottir, K.; Thorlacius, J. M.; Leppänen, S.; Bossi, R.; Skov, H.; Manø, S.; Patton, G. W.; Stern, G.; Sverko, E.; Fellin, P. Atmospheric monitoring of organic pollutants in the Arctic under the Arctic 
Monitoring and Assessment Programme (AMAP): 1993-2006. Sci. Total Environ. 2010, 408 (15), 2854-2873.

(5) Zhang, L.; Lohmann, R. Cycling of PCBs and HCB in the surface ocean-lower atmosphere of the open Pacific. Environ. Sci. Technol. 2010, 44 (10), 3832-3838.

(6) Mitra, S.; Bianchi, T. S. A preliminary assessment of polycyclic aromatic hydrocarbon distributions in the lower Mississippi River and Gulf of Mexico. Mar. Chem. 2003, 82 (3-4), 273-288.

(7) Feng, J.; Yang, Z.; Niu, J.; Shen, Z. Remobilization of polycyclic aromatic hydrocarbons during the resuspension of Yangtze River sediments using a particle entrainment simulator. Environ. Pollut. 2007, 149 (2), 193-200.

(8) Wang, J. Z.; Nie, Y. F.; Luo, X. L.; Zeng, E. Y. Occurrence and phase distribution of polycyclic aromatic hydrocarbons in riverine runoff of the Pearl River Delta, China. Mar. Pollut. Bull. 2008, 57 (612), 767-774.

(9) Macdonald, R. W.; Barrie, L. A.; Bidleman, T. F.; Diamond, M. L.; Gregor, D. J.; Semkin, R. G.; Strachan, W. M. J.; Li, Y. F.; Wania, F.; Alaee, M.; Alexeeva, L. B.; Backus, S. M.; Bailey, R.; Bewers, J. M.; Gobeil, C.; Halsall, C. J.; Harner, T.; Hoff, J. T.; Jantunen, L. M. M.; Lockhart, W. L.; Mackay, D.; Muir, D. C. G.; Pudykiewicz, J.; Reimer, K. J.; Smith, J. N.; Stern, G. A.; Schroeder, W. H.; Wagemann, R.; Yunker, M. B. Contaminants in the Canadian Arctic: 5 years of progress in understanding sources, occurrence and pathways. Sci. Total Environ. 2000, 254 (2-3), 93-234.

(10) Monirith, I.; Ueno, D.; Takahashi, S.; Nakata, H.; Sudaryanto, A.; Subramanian, A.; Karuppiah, S.; Ismail, A.; Muchtar, M.; Zheng, J.; Richardson, B. J.; Prudente, M.; Hue, N. D.; Tana, T. S.; Tkalin, A. V.; Tanabe, S. Asia-Pacific mussel watch: Monitoring contamination of persistent organochlorine compounds in coastal waters of Asian countries. Mar. Pollut. Bull. 2003, 46 (3), 281-300.

(11) Long, E.; Macdonald, D.; Smith, S.; Calder, F. Incidence of adverse biological effects within ranges of chemical concentrations in marine and estuarine sediments. Environ. Manage. 1995, 19, 81-97.

(12) Xu, Y.; Tian, C. G.; Ma, J. M.; Zhang, G.; Li, Y. F.; Ming, L. L.; Li, J.; Chen, Y. J.; Tang, J. H. Assessing environmental fate of $\beta$-HCH in Asian soil and association with environmental factors. Environ. Sci. Technol. 2012, 46 (17), 9525-9532.

(13) Tian, C.; Liu, L.; Ma, J.; Tang, J.; Li, Y. F. Modeling redistribution of $\alpha-\mathrm{HCH}$ in Chinese soil induced by environment factors. Environ. Pollut. 2011, 159 (10), 2961-2967.

(14) Wei, D. B.; Kameya, T.; Urano, K. Environmental management of pesticidal POPs in China: Past, present and future. Environ. Int. 2007, 33 (7), 894-902.

(15) Ding, X.; Wang, X. M.; Xie, Z. Q.; Xiang, C. H.; Mai, B. X.; Sun, L. G.; Zheng, M.; Sheng, G. Y.; Fu, J. M. Atmospheric hexachlorocyclohexanes ( $\mathrm{HCHs}$ ) in the North Pacific Ocean and the adjacent Arctic region: Spatial patterns, chiral signatures and sea-air exchanges. Environ. Sci. Technol. 2007, 41, 5204-5209.

(16) Zhang, G.; Li, J.; Cheng, H.; Li, X.; Xu, W.; Jones, K. C. Distribution of organochlorine pesticides in the Northern South China Sea: Implications for land outflow and air-sea exchange. Environ. Sci. Technol. 2007, 41 (11), 3884-3890.

(17) Lin, T.; Li, J.; Xu, Y.; Liu, X.; Luo, C.; Cheng, H.; Chen, Y.; Zhang, G. Organochlorine pesticides in seawater and the surrounding atmosphere of the marginal seas of China: Spatial distribution, sources and air-water exchange. Sci. Total Environ. 2012a, 435-436 (0), 244252.

(18) Nizzetto, L.; Lohmann, R.; Gioia, R.; Dachs, J.; Jones, K. C. Atlantic Ocean surface waters buffer declining atmospheric concentrations of persistent organic pollutants. Environ. Sci. Technol. 2010, 44 (18), 6978-6984.

(19) Komprda, J.; Komprdová, K.; Sáňka, M.; Možný, M.; Nizzetto, $\mathrm{L}$. Influence of climate and land use change on spatially resolved volatilization of persistent organic pollutants (POPs) from background soils. Environ. Sci. Technol. 2013, 47 (13), 7052-7059.

(20) Tian, C. G.; Ma, J. M.; Chen, Y. J.; Liu, L. Y.; Ma, W. L.; Li, Y. F. Assessing and forecasting atmospheric outflow of $\alpha-\mathrm{HCH}$ from China on intra-, inter-, and decadal time scales. Environ. Sci. Technol. 2012, 46 (4), 2220-2227.

(21) Zhang, G.; Parker, A.; House, A.; Mai, B.; Li, X.; Kang, Y.; Wang, Z. Sedimentary records of DDT and $\mathrm{HCH}$ in the Pearl River Delta, South China. Environ. Sci. Technol. 2002, 36 (17), 3671-3677.

(22) Yang, H. Y.; Xue, B.; Yu, P.; Zhou, S. S.; Liu, W. P. Residues and enantiomeric profiling of organochlorine pesticides in sediments from Yueqing Bay and Sanmen Bay, East China Sea. Chemosphere 2010, 80 (6), 652-659.

(23) Lin, T.; Hu, L.; Shi, X.; Li, Y.; Guo, Z.; Zhang, G. Distribution and sources of organochlorine pesticides in sediments of the coastal East China Sea. Mar. Pollut. Bull. 2012b, 64 (8), 1549-1555.

(24) Wang, T. Y.; Lu, Y. L.; Zhang, H.; Shi, Y. J. Contamination of persistent organic pollutants (POPs) and relevant management in China. Environ. Int. 2005, 31 (6), 813-821.

(25) Liu, J. P.; Li, A. C.; Xu, K. H.; Velozzi, D. M.; Yang, Z. S.; Milliman, J. D.; DeMaster, D. J. Sedimentary features of the Yangtze River-derived along-shelf clinoform deposit in the East China Sea. Cont. Shelf Res. 2006, 26 (17-18), 2141-2156.

(26) Liu, J. P.; Xu, K. H.; Li, A. C.; Milliman, J. D.; Velozzi, D. M.; Xiao, S. B.; Yang, Z. S. Flux and fate of Yangtze River sediment delivered to the East China Sea. Geomorphology 2007, 85 (3-4), 208224.

(27) Lim, D. I.; Choi, J. Y.; Jung, H. S.; Rho, K. C.; Ahn, K. S. Recent sediment accumulation and origin of shelf mud deposits in the Yellow and East China Seas. Prog. Oceanogr. 2007, 73 (2), 145-159.

(28) Dachs, J.; Eisenreich, S. J.; Baker, J. E.; Ko, F. C.; Jeremiason, J. D. Coupling of phytoplankton uptake and air-water exchange of persistent organic pollutants. Environ. Sci. Technol. 1999, 33 (20), $3653-3660$.

(29) Odabasi, M.; Cetin, B.; Demircioglu, E.; Sofuoglu, A. Air-water exchange of polychlorinated biphenyls (PCBs) and organochlorine pesticides (OCPs) at a coastal site in Izmir Bay, Turkey. Mar. Chem. 2008, 109 (1-2), 115-129.

(30) Qiu, X.; Zhu, T.; Wang, F.; Hu, J. Air-water gas exchange of organochlorine pesticides in Taihu Lake, China. Environ. Sci. Technol. 2008, 42 (6), 1928-1932.

(31) Möller, A.; Xie, Z.; Caba, A.; Sturm, R.; Ebinghaus, R. Occurrence and air-seawater exchange of brominated flame retardants and dechlorane plus in the North Sea. Atmos. Environ. 2012, 46 (0), 346-353.

(32) Cheng, J. O.; Ko, F. C.; Lee, C. L.; Fang, M. D. Air-water exchange fluxes of polycyclic aromatic hydrocarbons in the tropical coast, Taiwan. Chemosphere 2013, 90 (10), 2614-2622.

(33) Cetin, B.; Ozer, S.; Sofuoglu, A.; Odabasi, M. Determination of Henry's law constants of organochlorine pesticides in deionized and saline water as a function of temperature. Atmos. Environ. 2006, 40 (24), 4538-4546.

(34) Xiao, H.; Li, N.; Wania, F. Compilation, evaluation, and selection of physical-chemical property data for $\alpha$-, $\beta$-, and $\gamma$ hexachlorocyclohexane. J. Chem. Eng. Data 2004, 49, 173-185.

(35) Shen, L.; Wania, F. Compilation, evaluation, and selection of physical-chemical property data for organochlorine pesticides. J. Chem. Eng. Data 2005, 50 (3), 742-768.

(36) Poerschmann, J.; Kopinke, F. D. Sorption of very hydrophobic organic compounds (VHOCs) on dissolved humic organic matter (DOM). 2. Measurement of sorption and application of a FloryHuggins concept to interpret the data. Environ. Sci. Technol. 2001, 35 (6), 1142-1148.

(37) Hung, J. J.; Chen, C. H.; Gong, G. C.; Sheu, D. D.; Shiah, F. K. Distributions, stoichiometric patterns and cross-shelf exports of dissolved organic matter in the East China Sea. Deep Sea Res., Part II 2003, 50 (6-7), 1127-1145.

(38) Gao, J.; Liu, L.; Liu, X.; Lu, J.; Zhou, H.; Huang, S.; Wang, Z.; Spear, P. A. Occurrence and distribution of organochlorine pesticides - lindane, $p, p^{\prime}$-DDT, and heptachlor epoxide - in surface water of China. Environ. Int. 2008, 34 (8), 1097-1103. 
(39) Zhou, R. B.; Zhu, L. Z.; Yang, K.; Chen, Y. Y. Distribution of organochlorine pesticides in surface water and sediments from Qiantang River, East China. J. Hazard. Mater. 2006, 137 (1), 68-75.

(40) Tang, Z.; Huang, Q.; Yang, Y.; Zhu, X.; Fu, H. Organochlorine pesticides in the lower reaches of Yangtze River: Occurrence, ecological risk and temporal trends. Ecotoxicol. Environ. Saf. 2013, 87 (0), 89-97.

(41) Gong, X. Y.; Qi, S. H.; Wang, Y. X.; Julia, E. B.; Lv, C. L. Historical contamination and sources of organochlorine pesticides in sediment cores from Quanzhou Bay, Southeast China. Mar. Pollut. Bull. 2007, 54 (9), 1434-1440.

(42) Zhang, A.; Fang, L.; Wang, J.; Liu, W.; Yuan, H.; Jantunen, L.; Li, Y. F. Residues of currently and never used organochlorine pesticides in agricultural soils from Zhejiang province, China. J. Agric. Food Chem. 2012, 60 (12), 2982-2988.

(43) Wang, Q.; Zhao, L.; Fang, X.; Xu, J.; Li, Y.; Shi, Y.; Hu, J. Gridded usage inventories of chlordane in China. Front. Environ. Sci. Eng. 2013, 7 (1), 10-18.

(44) DeMaster, D. J.; McKee, B. A.; Nittrouer, C. A.; Jiangchu, Q.; Guodong, C. Rates of sediment accumulation and particle reworking based on radiochemical measurements from continental shelf deposits in the East China Sea. Cont. Shelf Res. 1985, 4 (1-2), 143-158.

(45) Li, Y.; Lin, T.; Chen, Y.; Hu, L.; Guo, Z.; Zhang, G. Polybrominated diphenyl ethers (PBDEs) in sediments of the coastal East China Sea: Occurrence, distribution and mass inventory. Environ. Pollut. 2012, 171 (0), 155-161.

(46) Zhao, Z.; Li, H.; Wang, Y.; Li, G.; Cao, Y.; Zeng, L.; Lan, J.; Wang, T.; Jiang, G. Source and migration of short-chain chlorinated paraffins in the coastal East China Sea using multiproxies of marine organic geochemistry. Environ. Sci. Technol. 2013, 47 (10), 50135022.

(47) Zeng, L.; Zhao, Z.; Li, H.; Wang, T.; Liu, Q.; Xiao, K.; Du, Y.; Wang, Y.; Jiang, G. Distribution of short chain chlorinated paraffins in marine sediments of the East China Sea: Influencing factors, transport and implications. Environ. Sci. Technol. 2012, 46 (18), 9898-9906.

(48) Lammel, G.; Ghim, Y. S.; Grados, A.; Gao, H.; Hühnerfuss, H.; Lohmann, R. Levels of persistent organic pollutants in air in China and over the Yellow Sea. Atmos. Environ. 2007, 41 (3), 452-464.

(49) He, J.; Balasubramanian, R.; Karthikeyan, S.; Joshi, U. M. Determination of semi-volatile organochlorine compounds in the atmosphere of Singapore using accelerated solvent extraction. Chemosphere 2009, 75 (5), 640-648.

(50) Jin, G. Z.; Kim, S. M.; Lee, S. Y.; Park, J. S.; Kim, D. H.; Lee, M. J.; Sim, K. T.; Kang, H. G.; Kim, I. G.; Shin, S. K.; Seok, K. S.; Hwang, S. R. Levels and potential sources of atmospheric organochlorine pesticides at Korea background sites. Atmos. Environ. 2013, 68 (0), 333-342.

(51) Ding, X.; Wang, X. M.; Wang, Q. Y.; Xie, Z. Q.; Xiang, C. H.; Mai, B. X.; Sun, L. G. Atmospheric DDTs over the North Pacific Ocean and the adjacent Arctic region: Spatial distribution, congener patterns and source implication. Atmos. Environ. 2009, 43 (28), 43194326.

(52) Jaward, F. M.; Barber, J. L.; Booij, K.; Dachs, J.; Lohmann, R.; Jones, K. C. Evidence for dynamic air-water coupling and cycling of persistent organic pollutants over the open Atlantic Ocean. Environ. Sci. Technol. 2004, 38 (9), 2617-2625.

(53) Lohmann, R.; Gioia, R.; Jones, K. C.; Nizzetto, L.; Temme, C.; Xie, Z.; Schulz-Bull, D.; Hand, I.; Morgan, E.; Jantunen, L. Organochlorine pesticides and PAHs in the surface water and atmosphere of the North Atlantic and Arctic Ocean. Environ. Sci. Technol. 2009, 43 (15), 5633-5639.

(54) Wu, X.; Lam, J. C. W.; Xia, C.; Kang, H.; Sun, L.; Xie, Z.; Lam, P. K. S. Atmospheric HCH concentrations over the marine boundary layer from Shanghai, China to the Arctic Ocean: Role of human activity and climate change. Environ. Sci. Technol. 2010, 44 (22), $8422-8428$

(55) Wurl, O.; Potter, J. R.; Obbard, J. P.; Durville, C. Persistent organic pollutants in the equatorial atmosphere over the open Indian Ocean. Environ. Sci. Technol. 2006, 40 (5), 1454-1461.
(56) Wong, F.; Jantunen, L. M.; Pućko, M.; Papakyriakou, T.; Staebler, R. M.; Stern, G. A.; Bidleman, T. F. Air-water exchange of anthropogenic and natural organohalogens on international polar year (IPY) expeditions in the Canadian Arctic. Environ. Sci. Technol. 2010, 45 (3), 876-881.

(57) Galbán-Malagón, C. J.; Berrojalbiz, N.; Gioia, R.; Dachs, J. The "degradative" and "biological" pumps controls on the atmospheric deposition and sequestration of hexachlorocyclohexanes and hexachlorobenzene in the North Atlantic and Arctic Oceans. Environ. Sci. Technol. 2013, 47 (13), 7195-7203.

(58) Li, J.; Zhang, G.; Qi, S. H.; Li, X. D.; Peng, X. Z. Concentrations, enantiomeric compositions, and sources of $\mathrm{HCH}, \mathrm{DDT}$ and chlordane in soils from the Pearl River Delta, South China. Sci. Total Environ. 2006, 372 (1), 215-224.

(59) Cheng, H.; Zhang, G.; Jiang, J. X.; Li, X.; Liu, X.; Li, J.; Zhao, Y. Organochlorine pesticides, polybrominated biphenyl ethers and lead isotopes during the spring time at the Waliguan Baseline Observatory, northwest China: Implication for long-range atmospheric transport. Atmos. Environ. 2007, 41 (22), 4734-4747.

(60) Bidleman, T. F.; Jantunen, L. M. M.; Helm, P. A.; BrorströmLundén, E.; Juntto, S. Chlordane enantiomers and temporal trends of chlordane isomers in Arctic air. Environ. Sci. Technol. 2002, 36 (4), 539-544.

(61) Gioia, R.; Nizzetto, L.; Lohmann, R.; Dachs, J.; Temme, C.; Jones, K. C. Polychlorinated biphenyls (PCBs) in air and seawater of the Atlantic Ocean: Sources, trends and processes. Environ. Sci. Technol. 2008, 42 (5), 1416-1422.

(62) Currado, G. M.; Harrad, S. Factors influencing atmospheric concentrations of polychlorinated biphenyls in Birmingham, U.K. Environ. Sci. Technol. 1999, 34 (1), 78-82.

(63) Offenberg, J. H.; Nelson, E. D.; Gigliotti, C. L.; Eisenreich, S. J. Chlordanes in the Mid-Atlantic atmosphere: New Jersey 1997-1999. Environ. Sci. Technol. 2004, 38 (13), 3488-3497.

(64) Lin, T.; Hu, Z. H.; Zhang, G.; Li, X. D.; Xu, W. H.; Tang, J. H.; $\mathrm{Li}, \mathrm{J}$. Levels and mass burden of DDTs in sediments from fishing harbors: The importance of DDT-containing antifouling paint to the coastal environment of China. Environ. Sci. Technol. 2009, 43 (21), 8033-8038.

(65) Gioia, R.; Li, J.; Schuster, J.; Zhang, Y. L.; Zhang, G.; Li, X. D.; Spiro, B.; Bhatia, R. S.; Dachs, J.; Jones, K. C. Factors affecting the occurrence and transport of atmospheric organochlorines in the China Sea and the Northern Indian and South East Atlantic Oceans. Environ. Sci. Technol. 2012, 46 (18), 10012-10021.

(66) Muir, D.; Lohmann, R. Water as a new matrix for global assessment of hydrophilic POPs. TrAC, Trends Anal. Chem. 2013, 46 (0), 162-172. 